\title{
OBITUARY: Jacob Willem Cohen
}

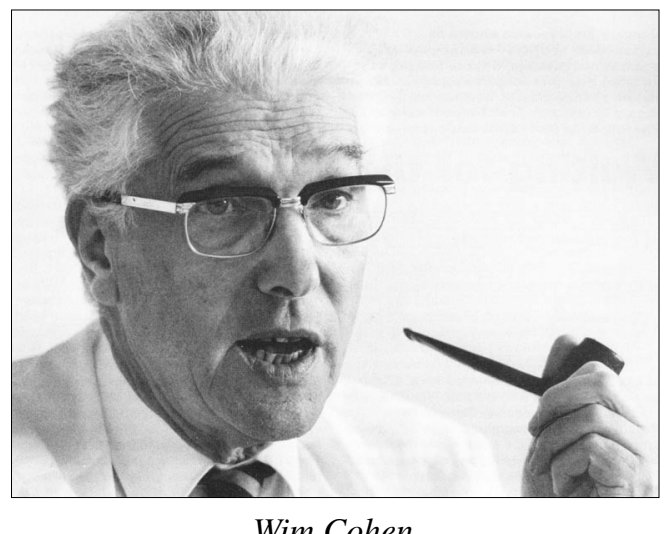

Wim Cohen

Jacob Willem (Wim) Cohen was born in Leeuwarden, The Netherlands, on August 27, 1923. After completing high school he spent a large part of World War II in hiding, with relatives and friends. During these years he acquired a deep knowledge of large parts of mathematics and physics by teaching himself. After the war, he studied mechanical engineering at Delft University of Technology. While studying at the university, he received an award for a university prize question on 'plastic buckling of a beam'. In 1949 he completed his Masters studies in Continuum Mechanics and Applied Mathematics (cum laude); and in 1955 he graduated cum laude, at Delft University of Technology, with a $\mathrm{PhD}$ thesis entitled 'On stress calculations in helicoidal shells and propeller blades' [4]. Like much of his later work, it concerned fundamental research in direct relation to practical engineering problems: his elegant and deep mathematical solution of the problem of stresses and displacements in helicoidal shells and ship propeller blades has proved of great importance in ship engineering building. This doctoral thesis unravelled an inconsistency in classical shell theory; the results of the thesis provided the basis for a sound strength calculation of wide blade ship propellers.

In the period 1950-1957, Cohen worked as a 'teletraffic engineer' in the Philips Telecommunication Group. About 1950, when Philips entered the field of telephone engineering, Cohen employed Southwell's relaxation method to solve the problem of leakage flux between the armature and core of a relay, which was an essential question in the design of telephone relays. Subsequently, he began a series of important investigations concerning the congestion analysis of telephone systems. His 1957 papers ([1], [5]-[8], [15]), in particular, make fundamental contributions to the existing congestion theory, and some of them (such as [6]) are still cited quite often. These papers contain, among other things, key ideas for the concepts of insensitivity and product form. Some twenty years later, when these concepts had been firmly established as basic elements of queueing network theory, Cohen was to make further fundamental contributions to them [12], [13]. For example, his generalization of the processor sharing concept in [13] leads to a pleasing unification and extension of many of the known product form and insensitivity 
results - and it allows the computer performance engineer to directly analyse an infinite variety of scheduling algorithms.

In the sixties, Cohen wrote several pioneering studies on stochastic processes and queueing theory. In 1964 he married Annette Waterman, the daughter of a distinguished professor of chemical technology. She created an ideal atmosphere for research and scholarship, which enabled Cohen to undertake the immense task of writing The Single Server Queue [9]. This monumental work, which firmly established Cohen as the world's leading queueing theorist, is still considered to be a standard work in the area of mathematical queueing theory. It set a standard of mathematical rigour which greatly enhanced the maturing of queueing theory as a mathematical discipline. One of its accomplishments is that it beautifully demonstrates the power of the method of Pollaczek in queueing theory. Basically, this method describes a physical queueing situation by analytic expressions (in terms of simple contour integrals), and thus transforms the probabilistic problem into a problem in complex analysis.

From 1957 until 1973, Cohen was Full Professor of Pure and Applied Mathematics and Mechanics in Delft University of Technology. On September 1, 1973, he left his Alma Mater and accepted the chair of Operations Research in the Mathematical Institute of the University of Utrecht. He stayed in Utrecht until his retirement in 1988, devoting much of his energy to research and teaching. He was an inspiring teacher, who asked many interesting questions and blended mathematical rigour with probabilistic and physical intuition. It was extremely important to him that his students would get the proper guidance on the way to attaining their degree. As an advisor of his PhD students, he was enormously stimulating and unselfish. He served the scientific community also in many other ways. He was one of the founding editors of the journal Stochastic Processes and their Applications, and he was one of the initiators of the series of yearly conferences of the same name, as well as of the International Teletraffic Congresses (ITC). He also served as an editor for a number of other leading journals, including the Applied Probability journals, and he was involved in the organization of several major international conferences and workshops in such areas as applied probability, queueing theory, computer performance, and teletraffic.

During his first Utrecht years, his research was mainly concerned with level crossings and with stochastic mean value theorems for regenerative processes. Many stochastic processes are regenerative, and Cohen showed how one can express the stationary distribution of such a stochastic process as a time average over one regenerative cycle. This makes it possible to apply relatively simple sample function relations. His level crossing technique was also based on a simple, yet fundamental, observation: a stationary regenerative stochastic process crosses each level in one cycle just as many times from below as from above. He subsequently exploited this observation to derive a wealth of interesting results (some of which were published in his book [11]), which found application in such areas as inventory theory, production theory, reliability, computer performance, and communications.

In the eighties and early nineties, his research focused on the analysis of two-dimensional random walks (a notoriously difficult problem), and their applications to computer-communications. He became absolutely fascinated by a technique, initiated by Fayolle and Iasnogorodski for the coupled processor model, to translate the problem of determining transforms of twodimensional queue length or workload probability distributions into the problem of solving a Dirichlet, Riemann, or Riemann-Hilbert boundary-value problem. Like the Pollaczek method, the idea was again to transform a probabilistic problem into a problem in complex analysis. Cohen's analytic power and stubborn tenacity finally allowed him to develop a solution method for a large class of two-dimensional random walk and queueing models (such as the shortest 
queue). The main ideas were presented in the research monograph [14]. In subsequent years he tried very hard to extend the method to higher dimensions. With characteristic optimism, he often claimed to be close, but he did not reach his goal. However, the research led to many other interesting results, mainly for two-dimensional random walks: hitting point identities for the process of hitting the boundaries of the random walk, ergodicity conditions, and stationary distributions. These results are presented in the book [23]. It also contains several results for $N$-dimensional random walks, with $N>2$, and brings within reach a numerical approach to a host of complex engineering problems (such as resource allocation, load balancing, and network dimensioning).

In 1988, in the middle of this research, Wim Cohen retired from the University of Utrecht (adhering to the mandatory retirement rules of The Netherlands). Around this time, many honours were bestowed upon him. In 1986 the Dutch Society of Sciences (Est. 1752) awarded him the prestigious Akzo prize, and in June 1988 he received an honorary doctorate from the Technion, Haifa. In the same year, he became an honorary member of the International Advisory Council of the Teletraffic Congresses, of which he had been an active member from the very beginning in 1955; in 1997 he received a Lifetime Achievement Award from the ITC. At his retirement, a conference in his honour was held, and the liber amicorum [2] was published.

After his retirement, Cohen continued to be very actively involved in research, while being affiliated with CWI (the Centre for Mathematics and Computer Science in Amsterdam) as an advisor. During the last five years, he devoted much energy to the study of heavy-tailed phenomena in queueing, a topic to which he had made pioneering contributions in the early seventies [3], [10]. Much of his work in the nineties was never submitted for publication, and was only published in CWI reports; these reports are listed below. His last CWI report appeared in September 2000, when his health had very much deteriorated-as he expressed it: 'The horizon has come nearer'. J. W. Cohen passed away in the early morning of November 12, after a bravely carried illness. He was buried in Haifa, Israel, on November 14. He leaves behind his wife, Annette, his three daughters (from his first marriage) and his son, who all occupied such an important place in his life. His son, Arjon, spoke these words about his father at the funeral:

To provide for his family was my father's desire-to some extent this sums him up. ... For him, providing for his family was not just providing material security, but was about providing the framework which unifies and perpetuates a family.

Wim Cohen has made a lasting impression on those who have interacted with him. Behind the smoke of his ever-present pipe and his formal, three-piece-suit-plus-sweater appearance was a warm and friendly personality. He was a religious man, who observed the rules of the Jewish religion without making it uncomfortable for others. He loved good food, history, chess-he enjoyed playing chess games with Julian Keilson-and conversations with friends on a wide range of topics. Until the very end, he was fascinated by mathematical issues, in particular those involving complex function theory. We feel his demise as a huge personal loss: as an advisor, colleague, and friend he has profoundly influenced and enriched our lives. Our thoughts are with Annette, who has always given him so much love and support.

Eindhoven University of Technology, Eindhoven

ONNO J. BOXMA

University of Maryland, College Park

RYSZARD SYSKI

February 2001 


\section{References}

[1] Beukelman, B. J. and Cohen, J. W. (1957). Call congestion of transposed multiples. Philips Telecommun. Rev. 17, 145-154.

[2] Boxma, O. J. And Syski, R. (eds) (1988). Queueing Theory and its Applications. Liber Amicorum for J. W. Cohen (CWI Monographs 7). North-Holland, Amsterdam.

[3] Callaert, H. and Cohen, J. W. (1972). A lemma on regular variation of a transient renewal function. $Z$. Wahrscheinlichkeitsth. 24, 275-278.

[4] CoHEn, J. W. (1955). On stress calculations in helicoidal shells and propeller blades. Doctoral Thesis, Delft University of Technology.

[5] CoHen, J. W. (1957). A survey of queueing problems occurring in telephone and telegraph traffic theory. In Proc. 1st Int. Conf. Operat. Res., Oxford. English Universities Press, London, pp. 138-146.

[6] CoHEn, J. W. (1957). Basic problems of telephone traffic theory and the influence of repeated calls. Philips Telecommun. Rev. 18, 49-100.

[7] Cohen, J. W. (1957). The full availability group of trunks with an arbitrary distribution of the inter-arrival times and a negative exponential holding time distribution. Simon Stevin 26, 169-181.

[8] Cohen, J. W. (1957). The generalized Engset formulae. Philips Telecommun. Rev. 18, 158-170.

[9] Cohen, J. W. (1969). The Single Server Queue. North-Holland, Amsterdam.

[10] Cohen, J. W. (1973). Some results on regular variation for distributions in queueing and fluctuation theory. $J$. Appl. Prob. 10, 343-353.

[11] CoHEn, J. W. (1976). On Regenerative Processes in Queueing Theory (Lecture Notes Econom. Math. Systems 121). Springer, Berlin.

[12] Cohen, J. W. (1979). On networks with generalized processor sharing and a new property of the Erlang Bformula. In Proc. 9th Int. Teletraffic Cong., Torremolinos, Spain.

[13] CoHen, J. W. (1979). The multiple phase service network with generalized processor sharing. Acta Informatica 12, 245-284.

[14] Cohen, J. W. And Boxma, O. J. (1983). Boundary Value Problems in Queuing System Analysis. North-Holland, Amsterdam.

[15] Cohen, J. W. ANd Jung, M. M. (1957). Calculations on a method for signal setting. Philips Telecommun. Rev. 17, 81-89.

\section{Recent publications}

We list here the recent publications of J. W. Cohen, in chronological order. The reader is referred to [2] for a complete list of earlier publications.

[16] Boxma, O. J., Cohen, J. W. And TiJms, H. C. (eds) (1986). Teletraffic Analysis and Computer Performance Evaluation. North-Holland, Amsterdam.

[17] Cohen, J. W. (1988). Boundary value problems in queueing theory. Queueing Systems 3, 97-128.

[18] Cohen, J. W. (1988). On entrance times of a homogeneous $N$-dimensional random walk: an identity. In $A$ Celebration of Applied Probability (J. Appl. Prob. 25A), ed. J. Gani. Applied Probability Trust, Sheffield, pp. 321-333.

[19] Cohen, J. W. and Pack, C. D. (eds) (1991). Queueing, Performance and Control in ATM (Proc. 13th Int. Teletraffic Cong. Workshop). North-Holland, Amsterdam.

[20] Boxma, O. J. And Cohen, J. W. (1991). The $M / G / 1$ queue with permanent customers. IEEE J. Sel. Areas Commun. 9, 179-184.

[21] Cohen, J. W. (1991). On the attained waiting time. Adv. Appl. Prob. 23, 660-661.

[22] Cohen, J. W. (1991). On two teletraffic congress programs: roots and scope. In Teletraffic and Datatraffic in a Period of Change (Proc. 13th Int. Teletraffic Cong.), eds A. Jensen and V. B. Iversen. North-Holland, Amsterdam, pp. 1059-1065.

[23] Cohen, J. W. (1992). Analysis of Random Walks. IOS Press, Amsterdam.

[24] Cohen, J. W. (1992). On the random walk with zero drifts in the first quadrant of $\mathbf{R}_{2}$. Stoch. Models 8, 359-374.

[25] Cohen, J. W. (1993). Complex functions in queueing theory. AEU 47, 300-310.

[26] CoHen, J. W. (1995). On a class of two-dimensional nearest-neighbour random walks. In Studies in Applied Probability (J. Appl. Prob. 31A), eds J. Galambos and J. Gani. Applied Probability Trust, Sheffield, pp. 207-237.

[27] Cohen, J. W. (1995). Two-dimensional nearest-neighbour queueing models, a review and an example. In Quantitative Models in Parallel Systems, eds F. Baccelli, A. Jean-Marie and I. Mitrani. Springer, Berlin, pp. 141152.

[28] CoHen, J. W. (1996). On periodic Pollaczek waiting time processes. In Athens Conference on Applied Probability and Time Series Analysis, Vol. I. Applied Probability (Lecture Notes Statist. 114), eds C. C. Heyde, Yu. V. Prohorov, R. Pyke and S. T. Rachev. Springer, New York, pp. 361-378. 
[29] Cohen, J. W. And Down, D. G. (1996). On the role of Rouché's theorem in queueing analysis. Queueing Systems 23, 281-291.

[30] Cohen, J. W. (1997). On the determination of the stationary distribution of a symmetric clocked buffered switch In Teletraffic Contributions for the Information Age (Proc. 15th Int. Teletraffic Cong.), eds V. Ramaswami and P. E. Wirth. North-Holland, Amsterdam, pp. 297-308.

[31] Boxma, O. J. And Cohen, J. W. (1998). The $M / G / 1$ queue with heavy-tailed service time distribution. IEEE J. Sel. Areas Commun. 16, 749-763.

[32] Cohen, J. W. (1998). Analysis of the asymmetrical shortest two-server queueing model. J. Appl. Math. Stoch. Anal. 11, 115-162.

[33] Cohen, J. W. (1998). On Ryszard Syski. J. Appl. Math. Stoch. Anal. 11, 223-224.

[34] Cohen, J. W. (1998). A heavy-traffic limit theorem for the $G I / G / 1$ queue with a Pareto-type service time distribution. J. Appl. Math. Stoch. Anal. 11, 247-254.

[35] Cohen, J. W. (1998). On the asymmetric clocked buffered switch. Queueing Systems 30, 385-404.

[36] Boxma, O. J. And Cohen, J. W. (1999). Heavy-traffic analysis for the $G I / G / 1$ queue with heavy-tailed distributions. Queueing Systems 33, 177-204.

[37] Boxma, O. J., Cohen, J. W. And Deng, Q. (1999). Heavy-traffic analysis of the $M / G / 1$ queue with priority classes. In Teletraffic Engineering in a Competitive World (Proc. 16th Int. Teletraffic Cong.), eds P. Key and D. Smith. North-Holland, Amsterdam, pp. 1157-1167.

[38] Boxma, O. J. And Cohen, J. W. (2000). The single server queue: heavy tails and heavy traffic. In Self-similar Network Traffic and Performance Evaluation, eds K. Park and W. Willinger. John Wiley, New York, pp. 143-169.

\section{CWI Reports}

Available at http://www.cwi.nl/static/publications/.

[39] Cohen, J. W. (1994). On the effective bandwidth in buffer design for the multi-server channels. Res. Rept BS-R9406.

[40] Cohen, J. W. (1994). On the analysis of the symmetrical shortest queue. Res. Rept BS-R9420.

[41] Cohen, J. W. (1994). Analysis of a two-dimensional algebraic nearest-neighbour random walk (queue with paired services). Res. Rept BS-R9437.

[42] Cohen, J. W. (1995). On the symmetrical shortest queue and the compensation approach. Res. Rept BS-R9519. Revised as Res. Rept BS-R9602 (1996).

[43] Cohen, J. W. (1996). On a zero-drift nearest-neighbour random walk. Res. Rept BS-R9615.

[44] Cohen, J. W. (1997). On the $M / G / 1$ queue with heavy-tailed service time distributions. Res. Rept PNA-R9702.

[45] Cohen, J. W. (1997). The $M / G / 1$ fluid model with heavy-tailed message length distributions. Res. Rept PNAR9714.

[46] Cohen, J. W. (1997). Heavy-traffic limit theorems for the heavy-tailed $G I / G / 1$ queue. Res. Rept PNA-R9719.

[47] Cohen, J. W. (1998). Heavy-traffic theory for the heavy-tailed $M / G / 1$ queue and $v$-stable Lévy noise traffic. Res. Rept PNA-R9805.

[48] Cohen, J. W. (1998). The v-stable Lévy motion in heavy-traffic analysis of queueing models with heavy-tailed distributions. Res. Rept PNA-R9808.

[49] Cohen, J. W. (2000). Random walk with a heavy-tailed jump distribution. Res. Rept PNA-R0010, to appear in Queueing Systems. 